\title{
Empirical Result: West and Central Africa Standardization on Port Logistics
}

\author{
Regine Adele Ngono Fouda
}

\begin{abstract}
This paper provided a case study on Cameroon's Port (the port of Douala) to further emphasize the need and benefits of strategic development obtainable through privatization, Port upgrading and terminal modifications. It's been tough; however, a radical reform upload is gradually making its way.

The paper will help West and Central Africa ports authorities in making, evaluating and realizing their decisions on port development, all in an effort to guaranty port efficiency and operational brilliance to profit the different ports, their hinterlands and their related clients. Therefore, this research found out the following issues related to West and Central Africa ports development as far as port logistics and transportation in general is concern.

Finally, a tactical development is needed which could likely have an impact on West and Central Africa's economy. This as a whole could boost the entire African nation's economy and eradicate poverty and unemployment. Moreover, most West and Central Africa countries have been experiencing ramshackle in commodity stocks of some of their key export commodities and long dwell time, making JIT delivery impossible in the supply chain as has been discussed. The principle of this paper is to bequeath the entire facet that operates as impediments to the West and Central Africa port's enhancement and enlargement.
\end{abstract}

Index Terms-Analysis of Hierarchical Process (AHP), Evaluation of West \& Central Africa (EWCA), port logistics, tactics.

\section{INTRODUCTION}

Global maritime transport has considerably changed in the last decade. Maritime transport is growing at a high pace. Container traffic is the fastest growing segment of maritime transport. Shipping lines have invested in ever growing containerships in order to benefit from economies of scale. In a global context, WCA maritime transport and port sectors face several long-term trends such as: Ship size, especially for container ships, will probably continue to increase in the region with subsequent demands on port efficiency and port infrastructure. Furthermore, Maritime transport tariffs should remain stable for the ports to be able to attract calls of mega-carriers (except if oversupply diminishes, which is unlikely to happen in the short and medium-term). In addition, International commitments on port security and environmental protection must not be neglected in WCA like it may have occurred in the past. The application of measures to enhance security, specifically the International Ship and

Manuscript received December 18, 2013; revised March 31, 2014.

Regine Adele Ngono Fouda is with the College of Logistics Engineering, Shanghai Maritime University, Shanghai, China (e-mail: reginemilena@yahoo.fr).
Port Facility Security Code (ISPS) Code, requires continuing attention.

\section{LITERATURE REVIEW}

The long-term strategic development is paramount for the successful integration into the global economic trends (McKinley study). Planning a successful business requires a managerial decision, which is directed toward the long-term management of entrepreneur/shareholder's wealth (Port) according to [1]-[4]. It carefully manages both tangible and intangible resources as well as the internal and external environment on which the port is operating.

Before thinking of a strategic development plan, it is mandatory to fully define the Vision and mission. They are the foundation on which the port strategic vision is laid upon. They are dominant to a good business policy and to its implementation. For a business that aims at leading an organization, it must react to the question "What do we want to be?" With a vision and clear objectives to follow; no matter the nature and size of the business, success can be guaranteed with great confidence. Despite the silver lining, Caution is still a necessity. A vision should be motivating the employees, entrepreneurs and also the customers relying on the business.

The ports in West and Central Africa long-term strategic development can be defined as those ports that can "open the new world, open the gate to the future" with unparalleled locations as the gateway to the entire Africa boost (port website), these ports do not only serve landlocked countries around their neighborhood [5], [6]; but also the coastal countries of other parts of Africa (north, East, south) and the Global economy in general as mentioned by [7]. These can be ports specialized to handle different types of cargo, negotiate concessionary contract agreement with the private sectors which are capable of providing quality operators as stated by [8] and capable of acquiring the expected large volumes of cargo and vessels which are necessary for constructing a modern port with advanced technical capacities.

The purpose of establishing a business organization particularly the Port should be directed towards a commercialization mission. Market-orientation therefore becomes the highest priority from which all other objectives tag along [9]. Consequently, the fundamental policy is what the company intends to follow. The mission therefore is the company's strength.

The mission of the ports of West and Central Africa can be determined as: We assist carriers to deliver their cargo to the place of destination. This is to elaborate the four operational functions associated with the port, which are: ship operation, 
transfer operation, storage operation and gate operation. Within this capacity, the ports of West and Central Africa can subsequently be capable to receive all kinds of ships, vessels, unload and reload them to accomplish business transactions.

The long-term tactical for a port should be planned such that, it considers the maximum use of all-natural human and financial resources invested. By efficiently managing the factors of production imputed in the port business, [10] also stated that a high level performance could be acquired as well as [11]. To maintain the continuous growth and development, maximum short-term and long-term decision-making is required for the survival of the business.

Once a tactical is set-up and adopted, still, an effective and efficient management is still required for its implementation because, a more generally accepted tactical does not necessary mean a successful one. To know if such a tactical is indeed the correct and best tactical; the following characteristics can be observed.

- It's been base on precise, accurate and reliable data with clear real-time benefits

- The tactical should guarantee little/negligible uncertainty,

- It's available and suitable for application under different conditions, and unforeseen circumstances should have a rescue and a backup measure.

- There should be a Possibility of implementing the tactical within the resources available to the organization.

- Profitability is guaranteed (through good hinterland connection for the ports).

- Competitiveness: looking into the companies weaknesses and making them the company's strength (in other words, building on the company's strength); as well as converting threats into opportunities.

- Forecasting the future and being dynamic enough to adapt to the change in management (Peter Drucker).

H01: Shipping line constrictions as well as low rate containerization might recuperate, if port logistics swab from public to private ownership management model.

H02: Ports and port logistics will have higher efficiency and productivity, if their internal cost is minimized to reach an international shipping service standard.

H03: Ports are willing to utilize their full capacity, especially when offered adequate maintenance facilities around and with no or less location constraint, i.e. no congestion.

H04: port performance will be prolific, if technological equipment (i.e. for logistic use) and routes to the hinterlands meet international standard according to ISO9001.

\section{THE THEORETICAL FRAMEWORK}

In psychology and in social sciences, theories have two critical components:

(a) The theory describes specific behavior(s), and (b) The theory must make predictions about future behaviors.

These theories are consequently used as the foundation of research studies such as this dissertation. Therefore, the researcher presents the theoretical framework to place this research within the perspective of other studies in the same discipline, such as [12]-[15]; pointed out in their various studies. The theoretical framework here provides support for this proposed study (see Fig. 1), by presenting known relationships among variables, concepts and setting limits or boundaries for the latter (see Fig. 2).

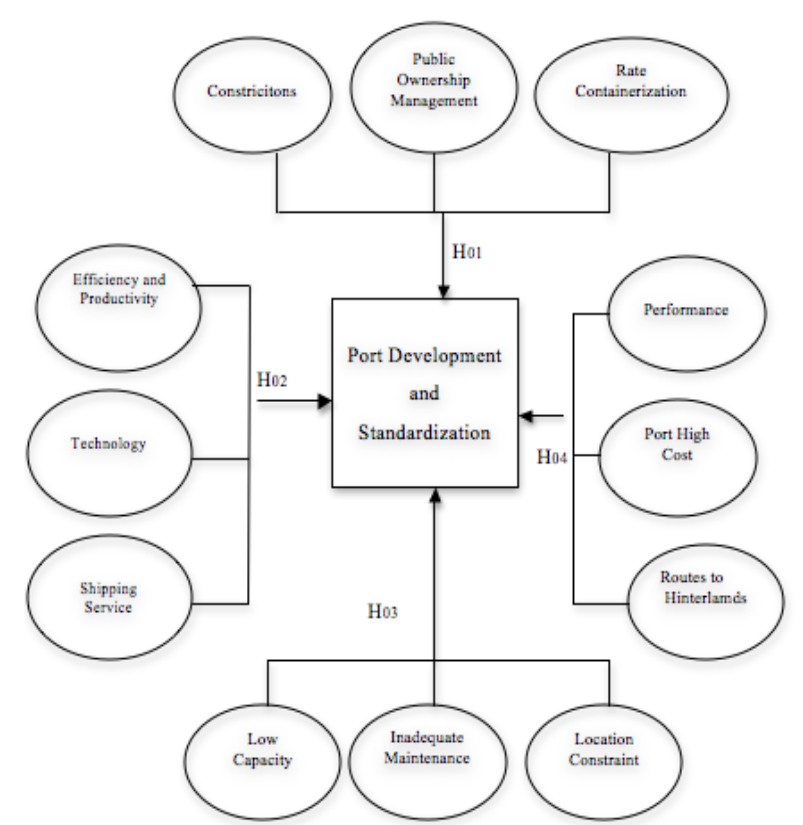

Fig. 1. The proposed model of the study.



Fig. 2. Conceptual model of the testing ports logistic development under Globalization.

\section{Methodology}

The Analytic Hierarchy Process (AHP) is a multi-criteria decision-making approach [16]-[18] and was introduced by [19]; [20]. The AHP has attracted the interest of many researchers mainly due to the nice mathematical properties of the method and the fact that the required input data are rather easy to obtain. The AHP is a decision support tool, which can be used to solve complex decision problems [8]. It uses a multi-level hierarchical structure of objectives, criteria, sub criteria, and alternatives [21]-[27]. Using a set of pair wise comparisons derives the pertinent data. These comparisons are used to obtain the weights of importance of the decision criteria, and the relative performance measures of the alternatives in terms of each individual decision criterion. If the comparisons are not perfectly consistent, then it provides a mechanism for improving consistency.

The structure of the typical decision problem considered in this paper consists of a number, say $M$, of alternatives and a number, say $N$, of decision criteria. Each alternative can be 
evaluated in terms of the decision criteria and the relative importance (or weight) of each criterion can be estimated as well. Let aij $(i=1,2 \ldots M$, and $N=1,2,3 \ldots N)$ denote the performance value of the $i^{\text {th }}$ alternative (i.e. $A i$ ) in terms of the $j^{\text {th }}$ criterion (i.e. $C j$ ). Also denote as $W j$ the weight of the criterion $C j$. Therefore, $M$ alternatives, $N$ criteria, $i=1,2 \ldots$ and $j=1,2,3 \ldots$ See the Table I.

TABLE I: THE ARRANGEMENT OF CHANNELS

\begin{tabular}{cccccc}
\hline \multicolumn{5}{c}{ Criterion } \\
\hline Alternatives & $\mathrm{C}_{1}$ & $\mathrm{C}_{2}$ & $\mathrm{C}_{3}$ & $\ldots \ldots$. & $\mathrm{C}_{\mathrm{N}}$ \\
& $\mathrm{W}_{1}$ & $\mathrm{~W}_{2}$ & $\mathrm{~W}_{3}$ & $\ldots \ldots$. & $\mathrm{W}_{\mathrm{N}}$ \\
$\mathrm{A}_{1}$ & $\mathrm{a}_{11}$ & $\mathrm{a}_{12}$ & $\mathrm{a}_{13}$ & $\ldots \ldots \ldots$ & $\mathrm{a}_{1 \mathrm{~N}}$ \\
$\mathrm{~A}_{2}$ & $\mathrm{a}_{21}$ & $\mathrm{a}_{22}$ & $\mathrm{a}_{23}$ & $\ldots \ldots \ldots$. & $\mathrm{A}_{2 \mathrm{~N}}$ \\
$\vdots$ & $\vdots$ & $\vdots$ & $\vdots$ & $\vdots$ & $\vdots$ \\
$\vdots$ & $\vdots$ & $\vdots$ & $\vdots$ & $\vdots$ & $\vdots$ \\
$\mathrm{A}_{\mathrm{M}}$ & $\vdots$ & $\vdots$ & $\vdots$ & $\vdots$ & $\vdots$ \\
\hline
\end{tabular}

Given the above decision matrix, the decision problem considered in this study is how to determine which the best alternative is. A slightly different problem is to determine the relative significance of the $M$ alternatives when they are examined in terms of the $N$ decision criteria combined.

In a simple Multi-Criteria Decision-Making (MCDM) situation, all the criteria are expressed in terms of the same unit (e.g. Euros). However, in much real life MCDM problems different criteria may be expressed in different dimensions (for example, weight, time, political \& environmental impact, etc). It is this issue of multiple dimensions, which makes the typical MCDM problem to be a complex one and the AHP, or its variants, may offer a great assistance in solving this type of problems.

TABLE II: THE SCALE OF RELATIVE IMPORTANCE ACCORDING TO [25]-1

\begin{tabular}{cll}
\hline $\begin{array}{l}\text { Intensity of } \\
\text { Importance }\end{array}$ & \multicolumn{1}{c}{ Definition } & \multicolumn{1}{c}{ Explanation } \\
\hline 1 & Equal importance & $\begin{array}{l}\text { Two activities contribute equally to the } \\
\text { objective }\end{array}$ \\
3 & Weak importance of one over another & $\begin{array}{l}\text { Experience and judgment slightly favor one } \\
\text { activity over another }\end{array}$ \\
5 & Essential or strong importance & $\begin{array}{l}\text { Experience and judgment strongly favor one } \\
\text { activity over another }\end{array}$ \\
\hline
\end{tabular}

Thus, they [28] introduced a variant of the original AHP, called the revised-AHP. Later, this was accepted as the previous variant of the AHP and now it is called the Ideal Mode AHP. Besides the revised-AHP, other authors also introduced other variants of the original AHP. However, the AHP (in the original or in the ideal mode) is the most widely accepted method and is considered by many as the most reliable MCDM method. [29] provided some axioms and guidelines on how close a near copy can be to an original alternative without causing a rank reversal. He suggested that the decision maker has to eliminate alternatives from consideration that score within 10 percent of another alternative. This recommendation was later sharply criticized by other authors (like afore mentioned [23]). The first step in the AHP is the estimation of the pertinent data. That is, the estimation of the aij and $W j$ values of the decision matrix. This is going to be seen in the next sub-section (see Table II).

\section{DAta Analyses}

One of the most crucial steps in many decision-making methods is the accurate estimation of the pertinent data. This is a problem not bound in the AHP method only, but it is crucial in many other methods, which need to educe qualitative information from the decision-maker. Very often qualitative data cannot be known in terms of absolute values. For instance," Which port logistic disproportional factors are the most influential on West and Central Africa ports?" Although information about questions like the previous one are vital in making the correct decision, it is very difficult, if not impossible, to quantify them correctly. Therefore, many decision-making methods attempt to determine the relative importance, or weight, of the alternatives in terms of each criterion involved in a given decision-making problem (see Table III).

TABLE III: THE SCALE OF RELATIVE IMPORTANCE ACCORDING TO [25]-2

\begin{tabular}{cll}
\hline $\begin{array}{l}\text { Intensity of } \\
\text { Importance }\end{array}$ & \multicolumn{1}{c}{ Definition } & \multicolumn{1}{c}{ Explanation } \\
\hline 7 & Demonstrated importance & $\begin{array}{l}\text { An activity is strongly favored and its } \\
\text { dominance demonstrated in practice }\end{array}$ \\
$2,4,6,8$ & $\begin{array}{l}\text { Antermediate values between the two } \\
\text { The evidence favoring one activity over } \\
\text { another is of the highest possible order of } \\
\text { affirmation } \\
\text { When compromise is needed }\end{array}$ \\
$\begin{array}{ll}\text { Reciprocals of } \\
\text { above nonzero }\end{array}$ & $\begin{array}{l}\text { If activity } i \text { has one of the above } \\
\text { nonzero numbers assigned to it when } \\
\text { compared with activity } j \text {, then } j \text { bas the } \\
\text { reciprocal value when compared with } i .\end{array}$ \\
\hline
\end{tabular}

\section{Decision Making Using PAIRWise CoMPARISON}

An approach based on pairwise comparisons, which were proposed by Saaty, has long attracted the interest of many researchers. Pairwise comparisons are used to determine the relative importance of each alternative in terms of each criterion. In this approach the decision-maker has to express his opinion about the value of one single pairwise comparison at a time. Usually, the decision-maker has to choose his answer among discrete choices. Each choice is a linguistic phrase. Some examples of such linguistic phrases are: "A is more important than B", or "A is of the same importance as B", or "A is a little more important than B", and so on (see the Table below).

The main problem with the pairwise comparisons is how to quantify the linguistic choices selected by the decision maker during the evaluation process [30]. All the methods used by the pairwise comparisons approach, eventually express the qualitative answers of a decision maker into some numbers which most of the time, are ratios of integers. Since pairwise comparisons are the keystone of these decision-making processes, correctly quantifying them is the most crucial step 
in multi-criteria decision-making methods, which use qualitative data.

Pairwise comparisons are quantified by using a scale. Such a scale is a one-to-one mapping between the set of discrete linguistic choices available to the decision maker and a discrete set of numbers, which represent the importance, or weight, of the previous linguistic choices. The scale proposed by Saaty is depicted in the first table below. Others have also proposed other scales. The values of the pairwise comparisons in the AHP are determined according to the scale introduced, as said above. According to this scale, the available values for the pairwise comparisons are members of the set: $\{9,8,7,6,5,4,3,2,1,1 / 2,1 / 3,1 / 4,1 / 5,1 / 6,1 / 7,1 / 8$, $1 / 9$ \} (see Table IV).

As an illustrative example, consider the following situation. Suppose that in the previous example of selecting port logistics disproportional factors in WCA, there are three alternative configurations, say A, B, and C. Also, suppose that one of the decision criteria is CRLLDE \& LCY, AMPLH (i.e. Containerization lingers low [31], despite efforts \& Low capacity in ports, Awkward measure and poor links to the hinterlands, etc.). Suppose that system A is much better than system B, and system C is the least desired one as far as the CRLLDE \& LCY criterion is concerned. Suppose that, the researcher is to follow the judgment matrix when the three alternative configurations are examined in terms of this criterion. Now, following the above supposition, the latter used the AHP calculation software by $C G I$ to compute the priority vectors and finding the Eigen values, $C I$ and $C R$.

TABLE IV: PCURIM \& PPSM CRITERION

\begin{tabular}{|c|c|c|c|c|}
\hline $\mathbf{C}_{1: \text { PCURIM/PPSM }}$ & $\overline{A_{1}}$ & $\overline{A_{2}}$ & $\mathrm{~A}_{3}$ & Priority Vector \\
\hline $\mathrm{A}_{1=\mathrm{A}}$ & 1 & 9 & 3 & 0.648355 \\
\hline $\mathrm{A}_{2=\mathrm{B}}$ & $1 / 9$ & 1 & $1 / 8$ & 0.0519494 \\
\hline $\mathrm{A}_{3-\mathrm{C}}$ & $1 / 3$ & 8 & 1 & 0.299696 \\
\hline
\end{tabular}

If finding the consistency index is equals to adding the columns in the judgment matrix and multiplying the resulting vector by the vector of priorities, therefore:

$$
\begin{gathered}
\lambda_{\max }=3.10785 \\
C I=0.0539237 \\
C R=0.092971
\end{gathered}
$$

This is to say that, $C R$ in this case $C_{1}$ is greater than 0.10 , therefore, it is a good idea to study the problem.

When system A is compared to system B for instance, then the decision-maker has determined that system $\mathrm{A}$ is to be classified as between "essentially more important" and "demonstrated more important" than system B (see table above). Thus, the corresponding comparison assumes the value of 6. A similar interpretation is true for the rest of the entries. One of the most practical issues in the AHP methodology is that it allows for slightly non-consistent pairwise comparisons. If all the comparisons are perfectly consistent, then the following relation should always be true for any combination of comparisons taken from the judgment matrix: $a i j=a i k a k j$.

However, perfect consistency rarely occurs in practice. In the AHP the pairwise comparisons in a judgment matrix are considered to be adequately consistent if the corresponding consistency ratio $(C R)$ is less than $10 \%$. The $C R$ coefficient is calculated as follows. First, the consistency index $(C I)$ needs to be estimated. This is done by adding the columns in the judgment matrix and multiplies the resulting vector by the vector of priorities (i.e. the approximated eigenvector) obtained earlier. This yields an approximation of the maximum eigenvalue, denoted by $\lambda_{\max }$. Then, the $C I$ value is calculated by using the formula: $C I=\left(\lambda_{\max }-n\right) /(n-1)$.

Next the consistency ratio $C R$ is obtained by dividing the $C I$ value by the Random Consistency index (RCI) as given in the Table V. If the $C R$ value is greater than 0.10 , then it is a good idea to study the problem.

TABLE V: RCI VALUES FOR DIFFERENT VALUES OF $N$

\begin{tabular}{llllllllll}
\hline $\mathrm{n}$ & 1 & 2 & 3 & 4 & 5 & 6 & 7 & 8 & 9 \\
\hline $\mathrm{RCI}$ & 0 & 0 & 0.58 & 0.90 & 1.12 & 1.24 & 1.32 & 1.41 & 1.45 \\
\hline
\end{tabular}

Furthermore, after the alternatives are compared with each other in terms of each one of the decision criteria and the individual priority vectors are derived, the synthesis step is taken. The priority vectors become the columns of the decision matrix (not to be confused with the judgment matrices with the pairwise comparisons). The weights of importance of the criteria are also determined by using pairwise comparisons. Therefore, if a problem has $M$ alternatives and $N$ criteria, then the decision maker is required to construct $N$ judgment matrices (one for each criterion) of order $M \times M$ and one judgment matrix of order $N$ $\times N$ (for the $N$ criteria). Finally, given a decision matrix the final priorities, denoted by $A^{i}{ }_{A H P}$, of the alternatives in terms of all the criteria combined are determined according to the following formula.

$$
A_{A H P=}^{i} \sum_{j}^{N}=1 a_{i j} w_{j}, \text { for } i=1,2,3 \ldots M
$$

Recall that in the case of the ideal mode AHP, dividing the largest entry in each column normalizes the columns of the decision matrix. All the above values are further illustrated in terms of a numerical paradigm. The numerical data for this example were adapted from an example given in.

\section{MORE NuMERICAL PARADIGM: 3-ALTERNATIVES AND 4-CRITERIA}

Suppose that the three alternatives: random selected WCA ports (i.e. Apapa port-Nigeria, Point Noir-Congo and Abidjan-Cote D'Ivoire) described earlier need to be evaluated in terms of the four decision criteria: PCURIM \& PPSM (Port Capacity usually Results from inadequate maintenance \& Port performance in WCA, slow motion), UDT \& HCPSSL (Undeveloped Technology \& High Costs of Port for Shippers and Shipping lines), AMPLH (Awkward measure and Poor links to the Hinterlands), and CRLLDE \& LCY (Containerization Rate lingers, despite Efforts \& Low Capacity). If more criteria are required to be considered, then this example can be expanded accordingly. Suppose that the following matrices represent the corresponding judgment matrices with the pairwise comparisons. Note that the corresponding priority vectors (for the individual criteria) are given (see Table VI-Table $\mathrm{X}$ ). 
TABLE VI: UDT \& HCPSSL CRITERION

\begin{tabular}{|c|c|c|c|c|}
\hline$\overline{\mathbf{C}_{2: \text { UDT \& HCPSSL }}}$ & $\mathrm{A}_{1}$ & $\overline{A_{2}}$ & $\mathrm{~A}_{3}$ & Priority Vector \\
\hline $\mathrm{A}_{\mathrm{l}=\mathrm{A}}$ & 1 & 5 & 4 & 0.673 \\
\hline $\mathrm{A}_{2=\mathrm{B}}$ & $1 / 5$ & 1 & $1 / 3$ & 0.101 \\
\hline$A_{3=C}$ & $1 / 4$ & 3 & 1 & 0.226 \\
\hline
\end{tabular}

TABLE VII: AMPLH CRITERION

\begin{tabular}{lcccc}
\hline $\mathrm{C}_{3: \mathrm{AMPLH}}$ & $\mathrm{A}_{1}$ & $\mathrm{~A}_{2}$ & $\mathrm{~A}_{3}$ & Priority Vector \\
\hline $\mathrm{A}_{\mathrm{l}=\mathrm{A}}$ & 1 & 4 & 3 & 0.625 \\
$\mathrm{~A}_{2=\mathrm{B}}$ & $1 / 4$ & 1 & $1 / 2$ & 0.137 \\
$\mathrm{~A}_{3=\mathrm{C}}$ & $1 / 3$ & 2 & 1 & 0.238 \\
\hline
\end{tabular}

$\lambda_{\text {max }}=3.018$

$\mathrm{CI}=0.009$

$\mathrm{CR}=0.016$

TABLE VIII: CRLLDE \& LCY CRITERION

\begin{tabular}{ccccc}
\hline $\mathbf{C}_{4: \text { CRLLDE \& LCY }}$ & $\mathrm{A}_{1}$ & $\mathrm{~A}_{2}$ & $\mathrm{~A}_{3}$ & Priority Vector \\
\hline $\mathrm{A}_{\mathrm{l}=\mathrm{A}}$ & 1 & 6 & 2 & 0.588 \\
$\mathrm{~A}_{2=\mathrm{B}}$ & $1 / 6$ & 1 & $1 / 4$ & 0.889 \\
$\mathrm{~A}_{3=\mathrm{C}}$ & $1 / 2$ & 4 & 1 & 0.323 \\
\hline$\lambda_{\max }=3.009$ & & & & \\
$C I=0.005$ & & & & \\
$C R=0.008$ & & &
\end{tabular}

Finally, the following is the judgment matrix for the case of comparing the importance of the four decision criteria.

TABLE IX: THE FOUR CRITERIA

\begin{tabular}{cccccc}
\hline The Four Criteria & $\mathrm{C}_{1}$ & $\mathrm{C}_{2}$ & $\mathrm{C}_{3}$ & $\mathrm{C}_{4}$ & Priority Vector \\
& & & & & \\
\hline $\mathrm{C}_{1}$ & 1 & 6 & 2 & 8 & 0.547 \\
$\mathrm{C}_{2}$ & $1 / 6$ & 1 & $1 / 2$ & 5 & 0.140 \\
$\mathrm{C}_{3}$ & $1 / 2$ & 2 & 1 & 7 & 0.271 \\
$\mathrm{C}_{4}$ & $1 / 8$ & $1 / 5$ & $1 / 7$ & 1 & 0.043 \\
\hline
\end{tabular}

$\lambda_{\text {max }}=4.151$

$\mathrm{CI}=0.0504$

$\mathrm{CR}=0.0560$

Then, the following decision matrix can represent the core of the typical Multi-Criteria Decision-Making (MCDM) problem: Criterion.

TABLE X: DECISION MATRIX

\begin{tabular}{crrrr}
\hline \multicolumn{5}{c}{ Criterion } \\
\hline Alternatives & $\mathrm{C}_{1}$ & $\mathrm{C}_{2}$ & $\mathrm{C}_{3}$ & $\mathrm{C}_{4}$ \\
& $\mathrm{~W}_{1=}(\mathbf{0 . 5 3 9 )}$ & $\mathrm{W}_{2=}(\mathbf{0 . 1 3 8})$ & $\mathrm{W}_{3=}(\mathbf{0 . 2 8 1})$ & $\mathrm{W}_{4-(\mathbf{0 . 0 4 2})}$ \\
$\mathrm{A}_{1}(\mathrm{~A})$ & 6 & 6 & 9 & 5 \\
$\mathrm{~A}_{2}(\mathrm{~B})$ & 7 & 1 & 1 & 1 \\
$\mathrm{~A}_{3}(\mathrm{C})$ & 1 & 7 & 5 & 3 \\
\hline
\end{tabular}

This is where:

$$
\begin{aligned}
& C_{1}=\text { PCURIM \& PPSM } \quad A_{1}=\text { Nigeria } \\
& C_{2}=\text { UDT \& HCPSSL } \quad A_{2}=\text { Congo } \\
& C_{3}=\mathrm{AMPLH} \quad A_{3}=\text { Cote D'Ivoire } \\
& C_{4}=\text { CRLLDE \& LCY }
\end{aligned}
$$

\section{CONCLUSION}

The purpose of this research was to reveal that, there are numerous aspects that operate as obstacle to WCA ports' improvement and maturity; hindering the latter to attain their desired strategic development endeavor, despite tremendous efforts to ascend. The objective of this research therefore was to understand how tactical planning can enable WCA ports remain lucrative and attractive, as well as see how these inabilities and constraints can be dodged, creating room for a boosted and complementary new-visional ports; this by building a coordinated network amongst the latters' ports, to serve as a vivid platform for cooperation and information sharing. This study was also guided by four hypotheses. Moreover, to have a better acquaintance of the aimed question answered below, it is judicious to note that; the researcher used SWOT method to analyze and determine the strategic objectives, as well as using multiple regression model and analytic hierarchy process (AHP) to establish the tactics in WCA ports; based on the tactical evaluation model of WCA ports (TEWCA), a multi-factor system analysis model of multi-objective optimization which was set to determine the latter's outstanding problem of variable, and the main factors that influence the realization of resources integration, expansion of port logistics under the management system. Furthermore, there was a case study of the Port of Douala (Cameroon), which has guiding significance. The data and variables at the end of the test showed how port logistics augment and descend frequently without a long period of stability.

Summarily, the main innovation points of this dissertation were: firstly, using SWOT method to analyze and determine the strategic objectives, WCA port orientation and the direction of development and the port development tactical in organizing framework. Secondly, analyzing port logistics based on port vitality and globalization, the transport cost reduction of WCA ports, port as a logistics center, development, in the port area of dry ports and inland port development, port network, tactical elements and tactical developments with means of implementation. Thirdly, using multiple regression model and analytic hierarchy process (AHP) establishing the tactics in WCA ports; (evaluation model of multi-objective optimization) this to determine the effective data and variables of the tactical elements of evaluation, and complementaring with the case study of the Port of Douala, Cameroon. Finally, based on the tactical evaluation model of WCA ports (TEWCA), multi-objective optimization of the latter analysis, determined the ports' outstanding problems of variables and criteria, which are the main factors that influence the ports.

\section{Results for Questions}

RQ1: Port concentration is limited (public owned). Therefore, can it reduce shipping line constraints, changing ownership to private management model, which in turn will confront low rate containerization?

According to hypothesis 1 (H01), Shipping line constrictions as well as low rate containerization might recuperate, if ports logistics swab from public to private ownership management model as tested above. The results showed that State's role in WCA ports is predominant, making port concentration higher for container traffic $\left(C_{4}=\right.$ $\lambda_{\text {max }}=3.009, C I=0.005, C R=0.008$ ), which is relatively low compared to the world ports standard, while shipping lines through conferences and tariffs erosion stoppage and 
required reconfiguration of shipping policy.

RQ2: What are the relevant incidents that occur in ports logistic under high costs of port productivity and efficiency for shippers \& shipping lines, as well as the crash on inadequate shipping services?

According to hypothesis 2 (H02) ports and port logistics will have higher efficiency and productivity, if their internal cost is minimized to reach an international shipping service standard. This was tested using both multi-regression and AHP analytic model. Due to ports logistic numerous constraints, port charges are extremely high for shippers $\left(C_{2}=\right.$ $\left.\lambda_{\max }=3.086, C I=0.043, C R=0.074\right)$. This is because, shipping lines face congestion costs and poor port productivity, therefore passing these costs to the shippers, who still believe WCA ports is a niche market. Moreover, shipping services face increased costs when calling in WCA due to inadequate or insufficient port equipment, poor port efficiency and low traffic.

Furthermore, a simple fact that, most ports are only having 2 gantry cranes which takes more time and causes congestion around the port area, increasing high cost for shippers and shipping lines on their goods. Solving such a factor will demand a lot of time and patience, due to the fact that, WCA port authority after establishing a strategic plan will need to get some machinery aid from their business partners of developing countries such as China, so as to install new technology and provide ability skills for the operators, this surely needs time and patience. However, this cannot be a vital guarantee of success and immediate change of congestion problems and port maintenance.

RQ3: Is the port's low capacity influenced by the latter's location, therefore resulting to inadequate maintenance?

According to hypothesis 3 (H03), ports are willing to utilize their full capacity, especially when offered adequate maintenance facilities around and with no or less location constraint, i.e. no congestion. As ports are increasingly challenged by intensified traffic, greater ship size and transshipment growth $\left(C_{4}=\lambda_{\max }=3.009, C I=0.005, C R=\right.$ $0.008)$ ports capacity may have to be expanded in the future. Also, when containerization rate substantially increases, capacity could then become a serious challenge in the region. Moreover, many ports are embedded in cities, resulting to congestion from land transport corridors, which are usually inadequate, requiring therefore better joint planning between ports and cities. Furthermore, the multi-regression and AHP analysis tested the hypothesis that, WCA ports capacity result to inadequate maintenance $\left(C_{1}=\lambda_{\max }=3.10785, C I=\right.$ $0.0539237, C R=0.092971$ ) in its equipment, dredging and navigational aids; however, there are few long-term contracts to work up dredging maintenance.

RQ4: Does undeveloped technology and poor links to the hinterlands have direct effect in achieving a stunning port performance?

According to hypothesis 4 (H04) port performance will be prolific, if technological equipment (i.e. for logistic use) and routes to the hinterlands meet international standard. A proper port can't actually function on a global trend without adequate machineries and technology. This is to effectively state that, efficient flow of information is considered to be an important variable within the ports $\left(C_{2}=\lambda_{\max }=3.086, C I=\right.$ $0.043, C R=0.074)$, therefore this requires cooperation, knowledge development and training, exchange of good practices, a port logistic management system and above all importance, acquire Information technology support for a better technical development of the port sector. Furthermore, a port's competitiveness does not only depend on its infrastructure and services, but on the quality and fluidity of the land transport networks $\left(C_{3}=\lambda_{\max }=3.018, C I=0.009, C R\right.$ $=0.016$ ), which serve it (most often being the regional interstate roads, see Fig. 5.3 above). Moreover, the number of container moves per crane hourly is usually 10 to $20\left(C_{1}=\lambda_{\max }\right.$ $=3.10785, C I=0.0539237, C R=0.092971)$, compared with 25 to 30 moves in the world ports.

After the final result from AHP analysis, regression analysis and the facts from the strategic formation and implementation, a lot have been put forth to improve west and Central Africa port logistics under the influence of globalization. However, one cannot certify that the eradication of all these ineffectiveness can amount to a new developed WCA as a whole, and a boom in their economy. Nevertheless, a lot will have increased, internally (port premises) as well as globally (in their respective WCA countries and other world countries in general), where business clients and collaborators from around the world will often come back for eventual business (see Table XI).

TABLE XI: THE ARRANGEMENT OF CHANNELS

\begin{tabular}{lllll}
\hline \hline Channels & Group 1 & Group 2 & $\cdots$ & Group $c$ \\
\hline Main channel & Channel 1 & Channel 2 & $\cdots$ & Channel $c$ \\
Assistant channel & Channel 2 & Channel 3 & $\cdots$ & Channel 1 \\
\hline \hline
\end{tabular}

\section{CONCLUSION}

A conclusion section is usually required. Although a conclusion may review the main points of the paper, do not replicate the abstract as the conclusion. A conclusion might elaborate on the importance of the work or suggest applications and extensions.

\section{ACKNOWLEDGMENT}

This has been an incredible work brought up here, patched up with zealous ideas by the author, as a result of her academic research. Therefore, I will firstly thank God almighty for His graces bestowed on me, and for making this piece of work available. Also, I will like to thank Dr. S. Rick Fernandez for his smartness and multi-task abilities in processing this paper. Last but not least, I will like to thank my beautiful family, all my friends and my lecturers at Shanghai Maritime University; without forgetting my supervisor Mr. Huang You Fang. Glory be to God, in the Highest.

\section{REFERENCES}

[1] N. Ravishankar and D. K. Dey, "A first course in linear model theory," Texts in Statistical Science, Chapman and Hall/CRC, December 21, 2001.

[2] E. Triantaphyllou and S. H. Mann, "An examination of the effectiveness of four multi-dimensional decision-making methods: a decision-making paradox," International Journal of Decision Support Systems, vol. 5, pp. 303-312, 1989.

[3] UNCTAD, Planning and Optimization of Seaports Operations, United Nations Publication on Ports Development TD/B/C4/42, 1991. 
[4] E. Triantaphyllou and S. H. Mann, "Some critical issues in making decisions with pairwise comparisons," in Proc. the Third International Symposium on the AHP, George Washington University, Washington, DC, 1994b, pp. 225-235.

[5] R. Heffernan, "Brave new` electronic' world," Containerization International, p. 57, June 1998.

[6] J. F. Raball and G. Marteau, "The cost of being landlocked: Logistics costs and supply chain reliability," The World Bank, Washington D.C., p. 99, 2010.

[7] C. Woodbridge, "Global operators consolidate hold on terminal market," Containerization International Handbook, p. 16, 2006.

[8] C. C. Ugboma, "Service quality in ports of a developing economy," Empirical Evidence from Nigerian Ports, Managing Service Quality, vol. 2, no. 2, pp. 20-21, 2006.

[9] M. Bengon, "An analysis of distribution of priority-values from alternative comparism scales within AHP," European Journal of Operations Research 140, pp. 104-117, 2002.

[10] M. A. Armstrong, Handbook of Human Resource Management Practice, 10th ed., Kogan Page, London, 2006.

[11] Z. Lim, "The comparative performance of public and private enterprises, the case of British Ports," Journal of Transport Economics and Policy, vol. 29, no. 3, pp. 263-274, 2004.

[12] D. A. Freedman, Statistical Models: Theory and Practice, Cambridge University Press, 2005.

[13] T. L. Saaty, "Fundamentals of decision making and priority theory with the AHP," Int. J. Services Sciences, vol. 1, no. 1. pp. 83-98, 1994.

[14] E. Triantaphyllou, P. M. Pardalos, and S. H. Mann, "A minimization approach to membership evaluation in fuzzy sets and error analysis," Journal of Optimization Theory and Applications, vol. 66, pp. 275-287, $1990 \mathrm{a}$.

[15] G. U. Yule, "On the theory of correlation," Journal of the Royal Statistical Society, vol. 60, no. 4, pp. 812-854, 1897.

[16] V. Belton and T. Gear, "On a short-coming of Saaty's method of analytic hierarchies," Omega, pp. 228-230, 1983.

[17] R. N. Wabalickis, "Justification of FMS with the analytic hierarchy process," Journal of Manufacturing Systems, vol. 17, pp. 175-182, 1988.

[18] T. O. Boucher and E. L. McStravic, "Multi-attribute evaluation within a present value framework and its relation to the analytic hierarchy process," The Engineering Economist, vol. 37, pp. 55-71, 1991.

[19] T. L. Saaty, "A scaling method for priorities in hierarchical structures," Journal of Mathematical Psychology, vol. 15, pp. 57-68, 1977.

[20] D. W. Miller and M. K. Starr, Executive Decisions and Operations Research, NJ: Prentice-Hall, Inc., Englewood Cliffs, U.S.A, 1969.

[21] K. E. Cambron and G. W. Evans, "Layout Design Using the Analytic Hierarchy Process," Computers \&IE, vol. 20, pp. 221-229, 1991.

[22] J. S. Dyer and R. E. Wendell, "A critique of the analytic hierarchy process," Working Paper, 84/85-4-24, Department of Management, the University of Texas at Austin, Austin, TX, 1985.
[23] J. S. Dyer, "Remarks on the Analytic Hierarchy Process," Management Science, vol. 36, pp. 249-258, 1990.

[24] D. Song and K. Yeo, "A competitive analysis of Chinese container ports using the analytic hierarchy process," Maritime Economics and Logistics, vol. 6, no. 1, pp. 34-52, 2004.

[25] T. L. Saaty, The Analytic Hierarchy Process, NY: McGraw-Hill, New York, U.S.A, 1980.

[26] T. L. Saaty, "Axiomatic foundations of the analytic hierarchy process," Management Science, vol. 32, pp. 841-855, 1983.

[27] T. L. Saaty, "An exposition of the AHP in reply to the paper 'Remarks on the Analytic Hierarchy Process'," Management Science, vol. 36, pp. 259-268, 1990.

[28] Chiwolka and Raith, "Group preference aggregation with the AHP implications for multiple issue agendas," European Journal of Operational Research, vol. 132, pp. 176-186, 2001.

[29] P. Putrus, "Accounting for intangibles in integrated manufacturing (nonfinancial justification based on the Analytical Hierarchy Process)," Information Strategy, vol. 6, pp. 25-30, 1990.

[30] M. Armstrong, Management Processes and Functions, London CIPD ISBN 0-85292-438-0, 1996.

[31] A. Bascombe, "Arvis stations," Containerization International, p. 39, May 1998.

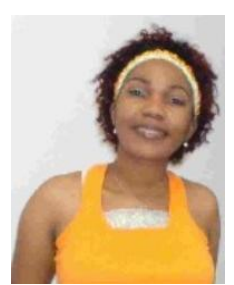

Regine Adele N. F. was born in Yaoundé City, Cameroon. She grew up in a strict obedient way with her father as guardian. Her love for sports and culture made it possible for her in secondary school to be in the ballet club, theatre club, social club, captain for the football and handball teams, president of UNESCO club etc. For bachelor degree, she read law and internship in a mayoral and bailiff office. She eventually studied and worked in a professional Italian Institute. She goes on to foster her study abroad where she obtained her $1^{\text {st }}$ masters in international politics in Belgium and a $2^{\text {nd }}$ masters in international trade in China. She acquired a lot of intellectual skills as an office intern-worker and an educator. She later on pursuits a higher diploma, where she graduates in 2013 with a doctorate degree from the department of Logistics Engineering (at SMU) in Shanghai, China. Dr Regine Adele is an academic and loves lecturing at the university. She has been an assistant lecturer in a university for a year. She had published some articles and had been in few academic conferences.

She is a hard working person who dreams of achieving greatness in this nowadays world. Success is what she strives for, despite several barriers she encounters. A key precept she learned on her way to success was to "keep positive no matter how heavy the storm might reign; the sun ends up fighting its way out." 